Revista Mídia e Cotidiano Artigo Seção Temática

Volume 13, Número 2, agosto de 2019

Submetido em: 17/06/2019

Aprovado em: 01/08/2019

\title{
"It's a match! You and Rio have liked each other": uma análise da representação identitária de estrangeiros no Tinder sob a luz da sociologia do cotidiano e do imaginário
}

"It's a match! You and Rio have liked each other": An analysis of foreigners' identity representation on Tinder, drawing from the sociology of the imaginary and the sociology of everyday life approaches

\author{
Naiara EVANGELO ${ }^{1}$ \\ Robson BRAGA ${ }^{2}$
}

\section{Resumo}

Este artigo propõe uma análise sobre a representação identitária de estrangeiros usuários do aplicativo de relacionamentos Tinder, no Rio de Janeiro, resultado de pesquisa que investigou as experiências de cidade e de sociabilidade desses viajantes suscitadas em interações iniciadas no aplicativo. A análise é feita a partir da revisão teórica da sociologia do imaginário fundada por Durand (1993) e do cotidiano de Maffesoli (1984), complementada pelas etapas empíricas inspiradas no método etnográfico de: a) observação feita diretamente no Tinder; b) entrevista, em trabalho de campo, com um dos usuários estrangeiros abordados na plataforma. No estudo, identificamos a recorrência de estereótipos identitários em interações sociais interculturais e analisamos como elas se expressam no Tinder e em interações iniciadas nele.

Palavras-chave: Identidade; Imaginário; Tinder.

\begin{abstract}
This article analyses the identity representation of foreign users of the relationship app Tinder in Rio de Janeiro. We discuss the results of a research project that investigated these travelers' sociability and city experiences through their interactions in the app's environment. The analysis is based on a literature review, incorporating perspectives from the sociology of the imaginary approach, established by Durand (1993), and from Maffesoli's (1984) concepts of everyday life (1984). The article also uses data from empirical research inspired by ethnography and conducted in two stages: a) observations conducted directly on Tinder; b) fieldwork interviews with foreign users of this platform.
\end{abstract}

\footnotetext{
${ }^{1}$ Doutoranda em Tecnologias de Comunicação e Cultura no PPGCOM da Universidade do Estado do Rio de Janeiro (UERJ). E-mail: naiaraevangelo@gmail.com.

2 Professor do Instituto de Cultura e Arte (ICA) da Universidade Federal do Ceará (UFC). E-mail: robsonsilvabraga2@gmail.com.
} 
The study identified the recurrence of identity stereotypes in intercultural social interactions and analysed how they express themselves in Tinder and through their interactions initiated via the app.

Keywords: Identity; Imaginary; Tinder.

\section{O cenário: A experiência de cidade mediada pelo Tinder}

Lançado em 2012, nos Estados Unidos, o aplicativo de relacionamentos Tinder ficou conhecido mundialmente por mediar de forma rápida o início de relações afetivas/sexuais e se tornou um dos aplicativos com mais popularidade no seguimento, com cerca de 26 milhões de combinações entre usuários por dia ${ }^{3}$, sinalizadas pela frase que intitula o artigo "It's a match" (essa é uma combinação, em tradução livre). Presente em mais de 190 países, ele se tornou popular entre usuários viajantes, sobretudo pela configuração paga "Passaporte", que permite escolher a geolocalização de busca por interagentes em outros países. Assim, os usuários podem fazer um uso muito particular do aplicativo: interagir com pessoas locais antes mesmo de chegar a seu destino e experienciar a cidade com as mesmas, proporcionando variadas possibilidades para além daquelas que um guia de viagem pode oferecer.

Em pesquisa que investigou as experiências de cidade e de sociabilidade de viajantes estrangeiros suscitadas em interações iniciadas no aplicativo, observamos que eram numericamente expressivas na plataforma as representações de usuários estrangeiros destacando elementos de suas identidades nacionais de origem. O presente estudo uniu a observação das representações no Tinder com a experiência de campo com usuário estrangeiro fora dela, com o intuito de entender como os imaginários culturais atravessam interações interculturais. Assim, a partir da sociologia do cotidiano e imaginário, o artigo apresenta uma análise desse fenômeno contemporâneo.

\section{"Imagens, símbolos e representações": sobre a sociologia do cotidiano e dos imaginários}

\footnotetext{
3 Informação presente no site oficial do Tinder. Disponível em: <https://www.help.tinder.com/hc/ptbr/articles/115004647686-O-que-\%C3\%A9-o-Tinder->. Acesso em: 20 mar. 2019.
} 


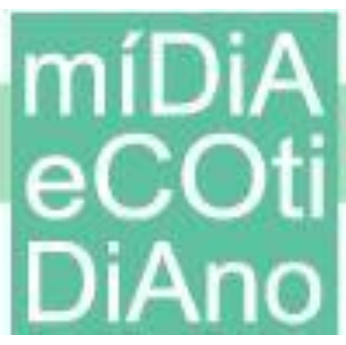

"Cidade maravilhosa", "Cidade-porto", "Cidade Olímpica", "Rio 40 C". Esses são alguns dos títulos que o Rio de Janeiro recebeu ao longo de sua história. Denominações que se relacionam diretamente com a forma como a capital fluminense foi representada por nativos e estrangeiros durantes séculos. Desde o início das observações preliminares no Tinder, houve a percepção de que os usuários recorriam a símbolos para suas autoapresentações na plataforma. Eles remetem, em geral, às características de personalidade, status sociais, gênero e, no caso específico de estrangeiros, às suas nacionalidades, como será analisado.

Autores da Sociologia considerada tradicional, como explicam Legros et al. (2014), ajudam a nortear o ponto de partida para pensar essas construções autobiográficas embasadas em imaginários. Da obra Secret et sociétés secretes, de Simmel, os autores (2014) extraem a sentença "toda relação entre os homens faz nascer em uma imagem do outro" (SIMMEL, 1991, p. 10 apud LEGROS et al., 2014, p. 70). De Émile Durkheim pensador que não abordaria, na análise dos pesquisadores (2014), uma reflexão específica sobre imaginário -, é interessante destacar a observação sobre representações coletivas. Elas nos levam a entender a sociedade como uma comunidade de ideias. Nesse contexto, o que ligaria os homens é a forma comum de pensar, ou seja, de representar as coisas. De Marcel Mauss, é constatado o elo entre as representações coletivas e simbólicas, a partir do qual "ele salienta uma antropologia geral de todos os fenômenos associados ao "imaginal"” (LEGROS et al., 2014, p. 81). Considerando-se que o fenômeno investigado se dá a partir de interações interpessoais, interessa-nos pensar justamente esse olhar sobre o outro e esse compartilhamento coletivo de experiências e ideias que será sistematizado pela Sociologia do imaginário e do cotidiano.

Para interpretar diretamente o movimento dos imaginários, recorremos à proposta de Legros et al., que enfatizam as diferentes noções que reportam a eles: a imagem, o símbolo e a representação social. Como explica Gilbert Durand (1993), um dos fundadores da Sociologia do Imaginário e inspiração dos estudiosos citados, sempre houve uma confusão na utilização dos termos relativos ao imaginário, devido à extrema desvalorização que sofreu a imaginação no pensamento do Ocidente e da Antiguidade clássica (DURAND, 1993). A partir daqui, usaremos os termos tais quais foram pensados pela corrente dessa sociologia. 
Malandragem? Hospitalidade? Cidade violenta? Pacificação? Paraíso? Cidade promíscua? Cidade amigável? Cidade acolhedora? Seja qual for a noção, a Sociologia do Imaginário - seguindo as premissas durandianas - pressupõe que, para interpretá-las, não é necessário buscar uma forma social secreta, pois os imaginários não estão escondidos. Muito pelo contrário, eles estruturam o entendimento da vida social. Ao mesmo tempo, eles lembram que “(...) interpretar não é nada... Nada além de uma maneira de criar novos imaginários ou, mais exatamente, as novas realidades do conhecimento" (LEGROS et al., 2014, p. 111).

Posto isso, partimos da evidência de que o imaginário é um pensamento simbólico, e ele só é símbolo porque há uma interpretação. Durand (1993) enfatiza que o símbolo pertence à categoria do signo e ajuda a economizar operações mentais em teoria, pois eles ganham significações coletivas. Nesse contexto, é preciso diferenciar dois tipos de signos: "os signos arbitrários puramente indicativos (...) e os signos alegóricos, que rementem para uma realidade significada dificilmente apresentável. Estes últimos signos são obrigados a figurar concretamente uma parte da realidade que significam" (DURAND, 1993, p. 10). Inspirado na teoria do texto de Paul Ricoeur, que afirma que a significação pode ser analisada na linguagem do objeto e na linguagem do ato, cobrindo todos os aspectos do discurso, exteriorizados ou não, Durand (1993) afirma que há uma metade visível e uma invisível no símbolo, sendo a invisível responsável por trazer um mundo de representações indiretas.

Pesquisas que são orientadas por uma perspectiva simbólica imaginária levaram à sistematização de formas distintas interpretativas. A que vamos assumir neste estudo é a busca pelo símbolo original, aquele que tem uma primeira realidade, mas que ganhou outros contornos históricos (LEGROS et al., 2014). Isso porque entendemos que os imaginários que medeiam as relações contemporâneas do Tinder não foram criados recentemente, possuindo justamente essa origem histórica.

O outro aspecto fundamental para entender os imaginários são as imagens, pois elas "se formam a partir da interação entre os reflexos (ou pulsões humanas) e o meio material e social" (idem, ibidem, p.121). Mas que reflexos seriam esses? Separar, interiorizar e religar. E é nesse movimento que a imagem se liga ao símbolo, pois ela se concretiza no que a Sociologia do Imaginário chama de arquétipo. Os arquétipos seriam os 
símbolos estáveis para além da cultura e os símbolos seriam as especificações culturais do mesmo. Pensando no Rio de Janeiro, as praias seriam arquétipos da cidade, mas os "corpos sarados" que circulam nela, por exemplo, são os símbolos culturais específicos das praias cariocas. Ou seja, o arquétipo da praia é similar em Barcelona ou no Rio de Janeiro, mas os símbolos que a cercam podem ganhar outras significações, que se deve a questões culturais. Sendo assim, entendemos o pressuposto dessa Sociologia que afirma que o mesmo símbolo tem diferentes sentidos no movimento do imaginário.

A última vertente para interpretar os imaginários é a da representação social, e ela pode ser pensada a partir de duas teses: a representação social ligada a uma imagem específica apropriada individualmente por um ator social; e a representação social como um mecanismo de aquisição das imagens vindas da imaginação. A primeira estaria ligada a um modo antropológico e/ou sociológico, com premissas de uma mentalidade coletiva e culturalmente determinada; e a segunda, como uma representação organizada pelo psiquismo, o que faria dessa representação algo inobservável pela sociologia. O que vemos é uma separação disciplinar entre uma perspectiva socioantropológica e outra da Psicologia. O que nos interessa de ambas as disciplinas é a concordância que as representações são comuns ao menos a algum grupo. "As representações sociais são, aqui, os universos das trocas próprias de um grupo cultural e dos objetos do ambiente do qual estes indivíduos dependem. Nesse caso, elas podem estar ligadas às opiniões, informações ou crenças" (idem, ibidem, p.130).

Com efeito, nada é unidimensional no seio da vida social. Esta, por numerosos aspectos, é monstruosa, fragmentada, e está sempre para além de onde acreditamos tê-la fixado. É seu pluralismo que a torna profunda. E esse estado de coisas é conveniente saber apreender. Eis então o que pretende fazer uma sociologia da vida cotidiana. E isso é justamente porque a existência - para além das diversas racionalizações e legitimações que conhecemos - está impregnada de todos esses "instantes obscuros", que não se pode fazer sua economia, e que se calcula, cada vez mais, o impacto na vida social (MAFFESOLI, 1984, p. 17).

Discípulo de Durand, Michel Maffesoli ficou conhecido por desenvolver a Sociologia da vida cotidiana, que observa, sobretudo, as vivências ordinárias. Em uma 
das obras em que demarca essa perspectiva teórica, Maffesoli (1984) afirma que devemos considerar o cotidiano como a ambiência em que se fundam os laços sociais. "É nesse sentido que o cotidiano deve ser compreendido como laboratório alquímico das minúsculas criações que pontuam a vida cotidiana, como lugar da 'recriação de si' e da manutenção da identidade que permite a resistência” (MAFFESOLI, 1984, p. 18).

O olhar de Maffesoli para o cotidiano agrega a análise ao estabelecer o contraponto à Sociologia do Imaginário de Durand. Além do olhar que lança sobre a vida cotidiana, Maffesoli (2012) tem investigado também um fenômeno embasado no desenvolvimento tecnológico, denominado por ele de realismo mágico. Para o sociólogo francês, no contexto temporal pós-moderno, esse imaginário renascente marca uma ruptura com a ideologia moderna, pois passaríamos de um "homem senhor do mundo" para a "idade dos povos".

Realismo, pois impregna todas as coisas da vida cotidiana; mágico, pois reveste essas mesmas coisas com uma aura imaterial, com um suplemento espiritual, com um brilho específico, contribuindo para fazê-las desempenhar o papel que tinha o totem para as tribos primitivas. (...) Eis o que é a fantasia pós-moderna. Ela não é destacada da existência cotidiana, mas é, no mais alto ponto, o coração que bate (MAFFESOLI, 2012, p. 107).

Essa perspectiva mágica e de aura imaterial nos leva a pensar sobre o mito. E, retomando a Sociologia do Imaginário, vale destacar o exemplo direto acerca dos imaginários sobre espaços, que incluem a cidade. Legros et al. (2014) ilustram o debate a partir do pensamento do intelectual francês Roger Caillois, que pontua como Paris encontra sua origem nos caracteres de sua figura mítica.

O imaginário espacial vai nascer das variações perceptíveis e sensíveis que uma experiência concreta e irredutível, mas bastante geral, inscreve na nossa prática cotidiana. Uma geografia sentimental das ruas e das edificações, àquela dos usos calculados e das obrigações. Sob esse ponto de vista, o dado objetivo não desaparece atrás da subjetividade e do talento descritivo do observador, mas dissemina um magnetismo próprio que desabrocha na magia atribuída a certos lugares (LEGROS; MONNEYRON; RENARD; TACUSSEL, 2014, p. 88). 
A figura mítica do Rio de Janeiro nasce justamente na vivência do cotidiano e desabrocha dessas paisagens e desses lugares que influenciaram em sua ascensão e disseminação, misturando o cotidiano das imagens e dos símbolos de Durand e o aspecto imaterial defendido por Maffesoli. Legros et al. (2014) delimitam que a Sociologia do Imaginário discute, assim, como os imaginários afetam nossa experiência histórica e nossa relação com o tempo, que não pode ser visto em uma trajetória linear. O "presente é modelado por imagens sincrônicas a ele e que permitem sua legibilidade" (LEGROS et al., 2014, p. 87).

Deste modo, encaminhamos a discussão para esse movimento de imaginários que foram construídos, desconstruídos, reconstruídos, que se transformam e se sobrepõem em uma perspectiva histórica, e que se apresentam em plataformas comunicacionais como imagens, músicas, mídias e, por fim, no Tinder. A partir da Sociologia do imaginário e da Sociologia da vida cotidiana, entendemos que devemos atentar ao coletivo, ao olhar sobre o outro e à vivência ordinária.

\section{O Rio entre imagens, músicas, mídias e o Tinder}

Em relato presente na obra "Histoire d'un voyage en terre de Brésil", o francês Jean Léry - que desembarcou na Baía de Guanabara em 1555 com o objetivo de fundar uma colônia que denominariam como França Antártica - retratou os nativos brasileiros como bárbaros e primitivos.

[...] Tudo me leva a crer que esses nativos são o povo mais bárbaro e estranho que existe sobre a terra. Eles vivem sem conhecimento de nenhum deus, sem inquietude de espírito, sem lei e sem nenhuma religião. Tal como animais, estão à mercê dos seus instintos. Tanto os homens como as mulheres andam completamente nus. A língua que falam é muito rica em sons, mas desprovida de numerais. Assim, quando eles querem expressar cinco, mostram os cinco dedos na mão (FRANÇA; RAMINELLI, 2009, p. 25).

Intitulada de "Inferno do Novo Mundo", a barbárie em que os nativos brasileiros viviam, relatada pelos viajantes franceses André Thevet, Jean Léry e Nicolas Barré, foi não só descrita em livros, mas também ilustrada em imagens que chegaram ao continente europeu e fizeram parte da construção de imaginários sobre o Brasil. Como 
ressaltam França e Raminelli (2009), as imagens concedem autenticidade visual ao testemunho dos viajantes. $\mathrm{Na}$ imagem, os nativos desnudos são representados como seres atormentados, que interagem com figuras com aspectos diabólicos, caracterizando o “inferno do Novo Mundo". Enquanto isso, os franceses, com suas vestimentas, mostram a sua civilidade no ambiente cercado pela natureza tropical, que inclui vegetação e mar.

\section{Imagem 1 - Inferno do Novo Mundo}

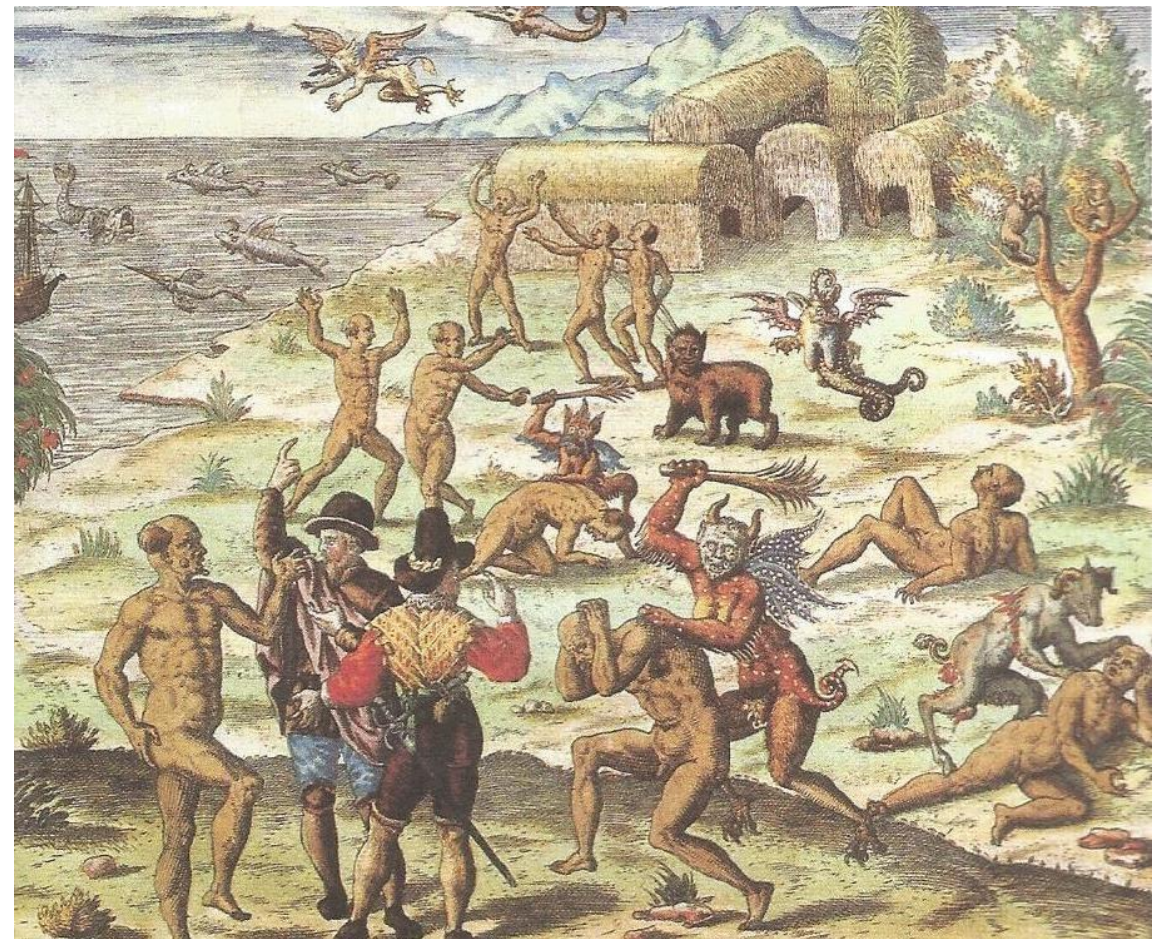

Fonte: Livro “Andanças pelo Brasil Colonial”, de Jean França e Ronald Raminelli (2009).

Por meio do relato e da imagem, é possível observar a comunicação de elementos a partir de representações sociais, que são partilhadas coletivamente, como ressalta a Sociologia do Imaginário. Percebemos, assim, como essas representações influenciam na construção de determinados imaginários que são difundidos nacional e internacionalmente.

Olhando para um cenário contemporâneo, a música brasileira tem forte papel na construção de imaginários sobre o Rio de Janeiro, e aqui estamos lidando com o imaginário tipo exportação. A Bossa Nova talvez tenha sido ao longo da história o 


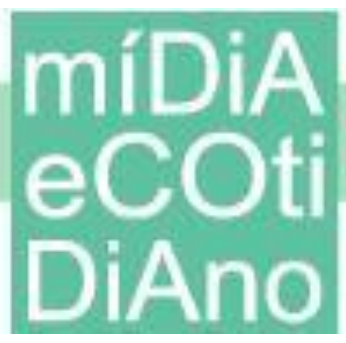

movimento musical carioca que mais enviou para fora do país símbolos sobre a cidade, seja por meio da representação da mulher brasileira ou das paisagens praianas. O clássico “Garota de Ipanema" (1962)4, de Tom Jobim e Vinicius de Moraes, e suas inúmeras traduções rodam o mundo até hoje. Mais recentemente, o clipe da música "Vai, malandra", lançado pela cantora carioca Anitta, em 18 de dezembro de 2017, entrou em pauta nas redes sociais, com críticas sobre a hipersexualização das mulheres e a forma como o espaço da favela ${ }^{5}$ foi representado. Tais críticas se voltavam ao fato de que o vídeo circularia o mundo todo, reforçando imaginários de hipersexualização da mulher brasileira e a favela carioca. Vale destacar que a cantora é a artista brasileira com maior projeção internacional no momento, com parcerias musicais com cantores latinos, como Maluma e Balvin, e a rapper americana Iggy Azalea.

Em uma publicação da Revista Veja, em sua página no Facebook, por exemplo, todos os comentários mais curtidos trazem críticas. "Brasil sempre conhecido pelas prostitutas e corrupção! Nada mudou!” [sic], comentou Israel Valladas, que recebeu 837 interações. Em quantidade de interações, o comentário acima foi seguido pelo de Wllian Oliveira, com 430 interações (“Os gringo do turismo sexual já tão até planejando a visitinha na favela durante o carnaval" [sic]); e pelo de Aline Gorga, com 548 interações:

Chulo, vulgar, nojento, apelativo, de extremo mau gosto... Algumas palavras para definir o novo clipe de Anita "Vai, malandra", que para além de vulgarizar a mulher brasileira, a mostra única e exclusivamente como um verdadeiro objeto sexual, um ser que tem valor apenas em razão de seu bumbum, e que, como uma cadela no cio, estaria pronta para "acasalar" (sim- pq ela é colocada como uma fêmea no cio) incansavelmente a qualquer momento e com qualquer um. Sem dúvida o pior clipe do ano, que passa uma péssima imagem do Brasil e da mulher brasileira, além de ser um desserviço e um péssimo exemplo para crianças e adolescentes. Triste o país que tem Anita com suas

\footnotetext{
${ }^{4}$ Olha que coisa mais linda / Mais cheia de graça / É ela, menina / Que vem e que passa / Num doce balanço / A caminho do mar / Moça do corpo dourado / Do sol de Ipanema / O seu balançado é mais que um poema / É a coisa mais linda que eu já vi passar / Ah, por que estou tão sozinho? / Ah, por que tudo é tão triste? / Ah, a beleza que existe / A beleza que não é só minha / Que também passa sozinha / Ah, se ela soubesse / Que quando ela passa / O mundo inteirinho se enche de graça / E fica mais lindo / Por causa do amor (Música: Garota de Ipanema; Compositor: Tom Jobim; Letrista: Vinicius de Moraes; Ano: 1962).

${ }^{5} \mathrm{O}$ clipe foi gravado no Vidigal, favela carioca que atrai passeios turísticos e está localizada à beira do mar, entre as praias do Leblon e de São Conrado.
} 
músicas de forte apelo sexual dentre uma de suas mais bem sucedidas cantoras, e que, às vésperas do Natal, tem muitos de seus cidadãos aplaudindo e cantando esse clipe que ela gravou. \#vergonhaalheia [sic]

Por sua vez, na publicação da página Quebrando o Tabu, no Facebook, de 18 de dezembro de 2017, os comentários mais curtidos destacavam a representatividade e a identificação do público feminino com o corpo da cantora, que decidiu não fazer retoques tão comuns nos corpos femininos expostos nos principais meios de comunicação. $\mathrm{O}$ comentário mais curtido, com 4,5 mil interações, foi o de Roberta Elias, que diz "Obg Anitta, por nos representar, por cada vez mais mostrar que somos todas lindas do nosso jeito" [sic]; seguido pelos comentários de Leo Feres, com 3,4 mil interações: “Anitta: a única instituição que funciona no Brasil" [sic]; e de Luziane Goulart, com 2,1 mil interações: "Entao, se ela pode ter celulite, pq eu... pobre falida, não posso...? kkkkkkk" [sic]; e de Wesley Magno, com 1,9 mil interações: "Mulher bonita é aquela que se sente bem consigo mesma. Mandou muito bem" [sic].

Percebemos que as críticas à cantora dialogam com uma insatisfação quanto aos imaginários sobre a mulher brasileira hipersexualizada, enquanto os elogios conversam com o empoderamento feminino, que defende que o corpo feminino pode o que ele quiser. O que parece rico nessa polêmica é a discussão sobre que Brasil queremos que os estrangeiros enxerguem internacionalmente. Quais símbolos quebrariam tabus? O de mulheres empoderadas? O da hipersexualização do corpo feminino? O da favela como espaço promíscuo? Percebemos aqui o poder interpretativo do símbolo ao qual a Sociologia do Imaginário se refere. A mesma representação ganha assim contornos paradoxais, de acordo com as conexões coletivas de distintos imaginários. Percebemos que o olhar para o clipe se diferencia pelo público dos canais de comunicação citados, sendo o primeiro o da Revista Veja, conhecida por um público mais conservador; e o segundo o da página Quebrando o Tabu, que o próprio nome conota para uma forma mais progressista de se pensar paradigmas.

As mídias tradicionais, como televisão e cinema, figuram também como exportadoras de imaginários sobre o Brasil. O longametragem brasileiro Cidade de Deus, por exemplo, dirigido por Fernando Meirelles e roteirizado por Braulio Mantovani, é um 
dos produtos culturais brasileiros mais conhecidos internacionalmente. $\mathrm{O}$ filme retratou o cotidiano da favela carioca Cidade de Deus, a partir da perspectiva do cotidiano, do crime e da pobreza.

Como conclui Rezende (2016) em sua análise sobre a potência imagética dos meios da comunicação na sociedade, em especial a TV:

\begin{abstract}
A televisão, enquanto meio de comunicação, 'inventa' imagens do mundo, transformando o sujeito e o mundo em múltiplas representações. No entanto, devemos deixar claro que o ato de representar não significa o ato de reproduzir: a representação é apreendida de um modo mais global, em um espaço cuja carga narrativa, a construção de uma diegese não está afastada (REZENDE, 2016, p. 75).
\end{abstract}

Gotardo (2016) faz sua análise em uma dinâmica inversa, observa como os estrangeiros nos representam a partir dos documentários de turismo. O que vale destacar nessa análise é a constatação certeira de que quem nunca esteve no Brasil dialoga com essas experiências que estão sendo representadas nas músicas, nos filmes, na televisão, nos documentários. E são esses consumos da brasilidade que impactam na criação desses imaginários a partir dos quais os estrangeiros chegam ao Brasil. Esses exemplos nos levam a pensar sobre as autorrepresentações que estrangeiros utilizam no Tinder no Rio de Janeiro, pois muitas delas estão atravessadas por imaginários que são difundidos por essas plataformas comunicacionais. Analisaremos a seguir como elas aparecem fora e dentro da plataforma.

\title{
A observação no Tinder
}

Se os estrangeiros chegam ao Brasil sendo chamados de "gringos", os cariocas e também os brasileiros residentes no Rio de Janeiro levam consigo pelo mundo um imaginário sobre o que é "ser brasileiro". Tal imaginário, em geral, é formado por uma combinação de elementos da nossa cultura. No presente estudo, denominamos os atores sociais como estrangeiros ${ }^{6}$ e brasileiros como residentes, talvez embasados em um

\footnotetext{
${ }^{6}$ Em definições do Dicionário Aurélio, estrangeiro seria “3. Que é de outra nação. 4. Que não é nacional”. Disponível em: <https://dicionariodoaurelio.com/estrangeiro> . Acesso em 15 de dezembro de 2017.
} 


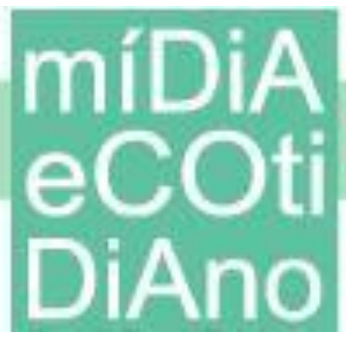

senso comum de que o primeiro é aquele que vem de fora, enquanto o segundo seria "nativo". Contudo, o questionamento que emerge é se essas categorias atendem as demandas complexas das sociedades cada vez mais em interações, em um processo de globalização, de um cenário multi/intercultural.

Essa problematização surge na esteira do pensamento de Stuart Hall (2013), um dos principais nomes dos Estudos Culturais britânico, que aponta uma crise em variadas disciplinas acerca do conceito de identidade e, ao mesmo tempo, afirma que é ainda possível pensá-lo sob rasura, sob condição de desconstruir os preceitos originais de identidade. Para o sociólogo, "é na tentativa de rearticular a relação entre sujeitos e práticas discursivas que a questão da identidade (...) volta a aparecer" (HALL, 2013, p. 105). A partir da percepção da recorrência a símbolos que ligam a uma identidade nacional, entendemos que, nas interações entre os estrangeiros usuários do Tinder no Rio de Janeiro e os brasileiros residentes na cidade, há uma construção discursiva muito própria aos viajantes em suas autorrepresentações.

O que notamos em observação na plataforma é que a forma como alguns usuários estrangeiros escolhem para alcançar a visibilidade em outras localizações é semelhante à feita por imigrantes nos séculos XIX e XX. Com um olhar estrangeiro, o historiador americano Lesser (2016) assume a difícil missão de falar de identidades nacionais no Brasil, considerando essa perspectiva relacional. Como o historiador ressalta, esses estrangeiros criaram as suas novas identidades quando chegaram ao país, e era uma das características pelas quais as pessoas se definiam, juntamente com a religião, gênero e classe (LESSER, 2016). No cenário de imigração europeia, o desrespeito com os negros já moradores do Brasil é um destaque, que, na perspectiva do autor, pode ser creditada ao medo dos imigrantes de serem colocados na categoria racial de não brancos. Podemos pensar em um imaginário de ressentimento coletivo de parte da população nativa brasileira com estrangeiros a partir de relatos desse período.

Uma das grandes histórias da invenção das identidades nacionais veio na forma de um diálogo que provavelmente nunca ocorreu. "Nós fizemos a Itália, agora temos que fazer os italianos, disse (ou teria dito) Massimo D'Azeglio, um estadista e escritor aristocrata, a Giuseppe Garibaldi, um outro estadista cujas proezas militares abrangeram da Itália ao Uruguai e Brasil. No entanto, esse "italiano", como também as 
outras identidades nacionais que tomaram forma nos séculos XIX e XX, não eram geradas apenas nos países de origem, mas também no exterior. (LESSER, 2016, p. 133).

Em relação ao cenário contemporâneo em que se insere o Tinder, é por meio de símbolos, imagens e imaginários que remetem às suas identidades que os usuários da plataforma se posicionam e constroem as suas personas virtuais. Para entender de forma mais nítida essas expressões de identidade no Tinder, analisamos ${ }^{7}$ seis perfis selecionados na plataforma para pensar o mecanismo de autorrepresentação com o objetivo de interagir com o outro, que, no caso, seria um "outro" de outra cultura.

\section{Imagem 2 - Perfis de estrangeiros no Tinder no Rio de Janeiro}

\footnotetext{
${ }^{7}$ Etapa empírica do presente estudo teve primeira discussão feita em artigo apresentado no XV Congresso Internacional Ibercom.
} 

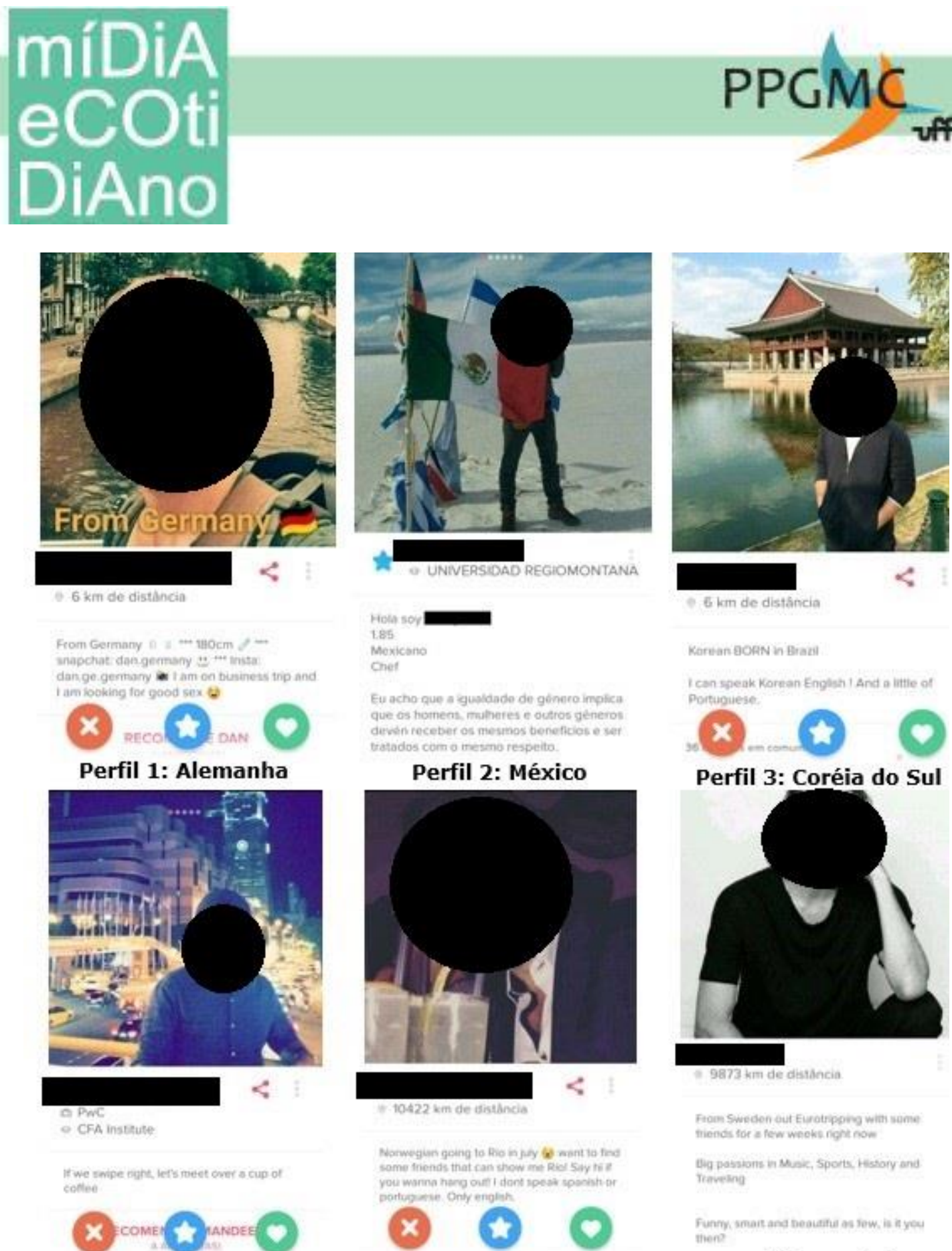

Perfil 4: Não identificada

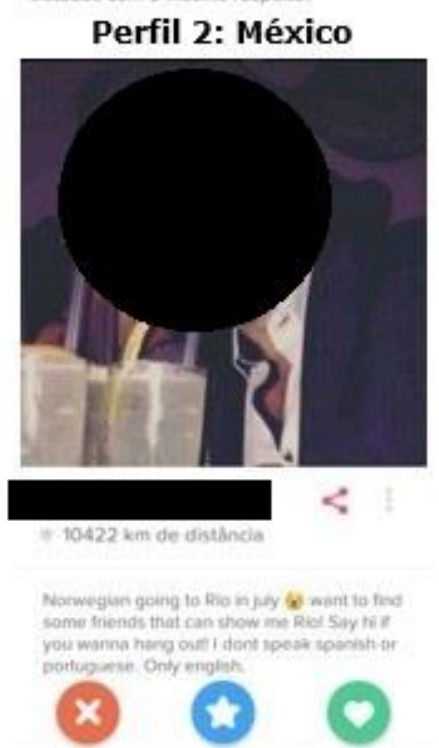

Perfil 5: Noruega

PPGMC uff

Fonte: Perfis recolhidos no Tinder, em pesquisa, no Rio de Janeiro.

Como é possível perceber nos seis perfis selecionados, os usuários utilizam, de alguma forma, símbolos que os remetem a alguma identidade nacional ou cultural. Os perfis 1, 2, 3, 4 e 6 colocam os seus países de origem no espaço da autobiografia, enquanto o perfil 5 não o faz. Em sua própria foto, o usuário do perfil 1 coloca a identificação "From Germany" (Da Alemanha, em tradução livre), seguida da bandeira da Alemanha. Por sua vez, o usuário do perfil 2 aparece em foto segurando a bandeira do México. 
O usuário do perfil 3 está em um cenário com uma construção tipicamente oriental. Além disso, ele faz questão de mostrar a vinculação com o Brasil em seu texto de autobiografia: "Korean Born in Brazil” (Coreano nascido no Brasil, em tradução livre). O usuário do perfil 4 é o único entre os seis perfis que não identifica a sua nacionalidade, mas está na imagem com um turbante, elemento-simbólico que marca a cultura de diversas nacionalidades. Vale destacar que os usuários dos perfis 5 e 6 estão usando a configuração "Passaporte", estando o primeiro a 10.422 quilômetros e o segundo a 9.873 quilômetros. Ou seja, os dois ainda não estavam no Rio de Janeiro. Sendo assim, ainda não estavam vivenciando a cidade in loco, mas por meio da mediação tecnológica.

O usuário 5 destaca, em sua autobiografia na plataforma, sua vinda para a cidade e a troca de localização: "Norwegian going to Rio in July (;) want to find some friends that can show me Rio! Say hi if you wanna hang out! I don't speak Spanish or Portuguese. Only English" (Norueguês indo para o Rio em julho :) quero fazer amigos que me mostrem o Rio! Diga Oi se você quer sair! Eu não falo espanhol ou português. Apenas inglês, em tradução livre). Sendo assim, o mesmo deixa claro que, para além de alguma possível interação, o Tinder seria uma forma de interagir com pessoas que possam mostrar a cidade, e aparece também um dos elementos centrais para a fluidez dessa interação, a língua. Ao dizer que só fala inglês, há um recorte de possibilidades de interações, e surge a fronteira simbólica da linguagem. Como veremos a seguir, ela é determinante nas experiências presenciais. Por sua vez, o perfil 2 não delimita a língua de interação e ainda utiliza um texto em português em sua autobiografia, demonstrando certa disposição a interações por meio da língua local.

Percebemos que o único usuário que apresenta características de sua personalidade, que são comuns entre usuários locais, é o perfil 6, ao citar a paixão por música e história, por exemplo. Sendo assim, para os demais, as suas identidades nacionais prevalecem quanto ao objetivo das interações que buscam estabelecer no Rio de Janeiro.

Vimos também que o perfil 1 enfatiza a frase "Looking for good sex" (procurando por bom sexo, em tradução livre). Ainda que o aplicativo tenha se tornado, pela forma de uso da maioria dos usuários, uma ambiência de busca por relacionamentos afetivo-sexuais, a pergunta que nos colocamos é se essa mensagem seria destacada se o 
mesmo usuário estivesse em qualquer outro país ou em seu país local ou se ela está ligada ao imaginário sobre um Brasil "sensual", sobre um "paraíso sexual”, conformado ao longo de anos de história.

Ao analisar a criação de personas no Facebook, "entendendo o termo 'persona' (de mesma raiz etimológica de 'personagem', do latim per sonare que significa 'soar através de')", Polivanov (2014, p. 198) explora a perspectiva da pesquisadora estadunidense Danah Boyd, que defende que, nos ambientes de sites de redes sociais, os perfis devem ser vistos como uma construção discursiva direcionada a um público. A autora (2014, p. 199) conclui, assim, que persona não carrega o sentido de uma construção falsa ou enganosa, mas se trata de uma versão de si, "selecionando comportamentos e materiais de acordo com a impressão que querem causar à sua audiência em determinado momento".

Trazendo essa a análise para esse estudo, percebemos que os perfis recolhidos ilustram como essa experiência específica no Tinder estimula que alguns estrangeiros busquem em suas identidades nacionais e culturais uma forma de estabelecer suas interações em outro local. Tais rasuras se apresentaram em formas distintas de análise, seja em uma perspectiva individual, seja na relação com o outro. Outra perspectiva importante é como essas construções das autorrepresentações perpassam os imaginários sobre localidades, seja por meio de imagens e símbolos utilizados, seja pelo discurso, como identificamos. A seguir, analisaremos como determinados imaginários sobre identidades nacionais aparecem em interação suscitada no aplicativo.

\section{Não existe bandeira do México no Saara}

Poderíamos polemizar à vontade, mostrando como o cotidiano, tão ignorado antes, tornou-se uma temática importante para todos aqueles que pretendem compreender, de maneira profunda, a vida social. Poderíamos também ironizar a conversão daqueles que, após terem reprovado seu aspecto frívolo, tornaram-se os zeladores tonitruantes da força viva do presente. (...) Talvez seja melhor ver o que, traçando com obstinação seu caminho, a temática do cotidiano trouxe de contribuição para a compreensão da sociedade pós-moderna. (MAFFESOLI, 1984, p. 16). 
Para encerrar o estudo dessa experiência contemporânea de cidade mediada tecnologicamente, apostamos na experiência cotidiana da conversa. Apresentamos assim o relato da experiência de campo suscitada por meio do Tinder, na qual A. ${ }^{8}$ aceitou participar como colaborador da pesquisa. Como procedimento metodológico para esta etapa específica, um dos autores desta pesquisa adotou o método da observação participante a fim de obter maior contato com um estrangeiro usuário do Tinder no Rio de Janeiro. A pesquisadora propôs ser uma espécie de "anfitriã" para o estrangeiro, colaborando, assim, com a sua experiência de cidade mediada inicialmente pelo Tinder. Com inspiração etnográfica, foram três meses de interações com A., desde o primeiro contato pelo Tinder até o último encontro presencial, na semana em que ele deixou o Rio de Janeiro. Logo no começo da interação, deixou-se clara a intenção de pesquisa. Após a informação, a resposta dada foi "pesquisame" [sic] (pesquisa-me, em espanhol). As trocas com A. passaram a ser analisadas com um olhar sistematizado, tendo surgido a partir de um interesse mútuo. Ele queria conhecer a cultura e melhorar o português, enquanto que os pesquisadores queriam acessar e analisar a experiência de cidade mediada inicialmente pelo Tinder.

O primeiro encontro presencial foi em um café no Parque Lage, no Bairro Jardim Botânico. O local foi escolhido pelo colaborador da pesquisa. Questionado o motivo, ele explicou que havia lido que era perto da natureza e tinha uma bela vista para o Cristo Redentor. Na época, A. estava hospedado em Copacabana, e os colegas de hostel funcionavam como informantes sobre a cidade.

Logo no início da conversa, surgiu uma dificuldade de comunicação. Ele não entendia completamente o português. Incomodado, A. em algum momento da conversa começou a falar em inglês e, por alguns minutos, fluiu. Um mexicano e uma brasileira falando em inglês no Brasil? A conversa foi retomada em "portunhol" e, com o intuito de fazer a conversa fluir, o assunto se tornou Usurpadora (novela), Maria do Bairro (novela), Chaves (seriado infantil), produtos midiáticos do México que fizeram sucesso na televisão brasileira. Sendo assim, recorrer às representações do México que faziam parte

\footnotetext{
${ }^{8}$ A identidade do colaborador da pesquisa foi preservada, e será sinalizada pela abreviação “A.”.
} 


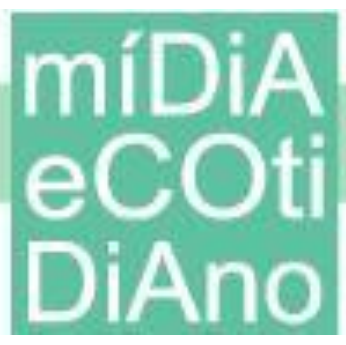

do imaginário da pesquisadora foi o caminho para encontrar uma sinergia no diálogo. Depois das novelas, futebol e a cidade foram temáticas que apareceram.

Definitivamente, a temática da cidade era a que mais interessava a ele. A. queria saber aonde ir, lugares onde se hospedar, sobre os melhores restaurantes, localidades noturnas, praias, entre outros. Mostrou fotos no celular de locais a que gostaria de ir, como o Morro Dois Irmãos, ponto mais alto do morro onde também se situa a comunidade do Vidigal, na Zona Sul carioca. Foi explicado onde ele estava localizado, próximo à Praia de Ipanema. Surpreendentemente, na semana seguinte, ele havia se mudado para um hostel no Vidigal. A. enviou uma mensagem do alto do Dois Irmãos, demonstrando empolgação e dizendo que queria compartilhar essa experiência.

Alguns dias depois, o encontro seguinte foi na Rua do Ouvidor, no Centro do Rio de Janeiro, escolha da pesquisadora, que presumiu que A. gostaria de conhecer o clima mais boêmio da cidade, saindo do eixo Zona Sul. Nesse segundo encontro, ele demonstrava maior domínio do português, e a comunicação passou a fluir mais facilmente. Vale ressaltar que, entre o primeiro e o segundo encontro, foram trocadas mensagens diariamente no Whatsapp ${ }^{9}$ e dicas sobre a cidade e também sobre português.

Dessa vez, uma novidade: as questões de A. eram sobre Niterói, cidade vizinha à capital fluminense. Ele contou que havia recebido um convite para trabalhar na cozinha de um hostel de lá. Ele estava há três semanas na cidade e já tinha morado em Copacabana e Vidigal e, agora, estava considerando ir para Niterói. A. queria informações detalhadas sobre o custo de vida, sobre o cotidiano e sobre locais para explorar. Dias depois, uma mensagem sobre a experiência de trabalho na terra de Arariboia. A. conheceu bairros da Região Oceânica de Niterói, fez novos amigos e parecia não precisar mais de dicas da cidade.

Depois de alguns dias sem comunicação, A. informou que tinha acabado de se mudar para Ilha da Gigoia, um refúgio na natureza em plena Barra da Tijuca, bairro na Zona Oeste da cidade do Rio de Janeiro. Em mais um encontro, ele parecia outra pessoa.

\footnotetext{
${ }^{9}$ A Transição do Tinder para o Whatsapp aconteceu no segundo dia de interação. O aplicativo de mensagens é mais eficiente, sobretudo no sentido de imediatismo, considerando que a notificação de mensagens do Tinder é lento e, as vezes, falha. A transição entre os aplicativos pode significar um maior interesse entre as partes envolvidas.
} 


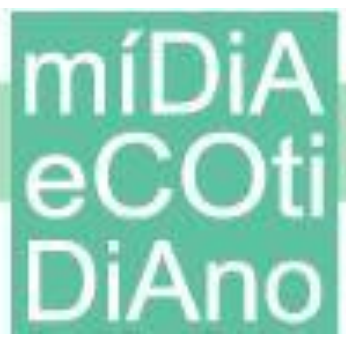

O domínio do português era perceptível, já conhecia muito sobre a cidade e sabia exatamente o porquê de estar ali: "Queria conhecer o máximo possível do Rio, de Copacabana até a Ilha da Gigoia”. Um conhecimento limitado, portanto, à região oceânica (e mais turística) da cidade. A conversa não era mais dominada pela temática da cidade, mas por experiências pessoais que passavam pelas percepções sobre as relações interpessoais com brasileiros e outros estrangeiros residentes no Brasil. A temática deixou de ser, portanto, sobre o local e passou a ser sobre as diversas identidades que viviam ali, não se limitando aos aspectos culturais, mas de comportamento, a exemplo da forma grosseira como seu chefe brasileiro lidava com seus funcionários.

Passados mais alguns dias, A. entrou em contato: "Você sabe onde comprar uma bandeira do México aqui, no Rio?". Seguimos, então, para um longo dia ao Saara (Sociedade de Amigos das Adjacências da Rua da Alfândega), um dos mais conhecidos centros populares de comércio no Centro do Rio de Janeiro. Entramos em quase uma dezena de lojas em busca da bandeira do México. Para nossa surpresa, não havia bandeira do México no Saara! É possível comprar bandeiras da China, dos Estados Unidos, do Chile, da Argentina, de Portugal, da Espanha... Mas não bandeira do México. O máximo que conseguimos foi uma loja que poderia mandar confeccionar a bandeira, o que demoraria em torno de quinze dias. Foi neste momento que A. contou que estava pensando em continuar a sua viagem pela América do Sul e queria a bandeira para usar na estrada para pedir carona.

A ideia da bandeira foi abandonada e compramos material para fazer um cartaz com pedidos de carona e desenhamos uma bandeira do México. Enquanto fazíamos, aconteceu algo que não havia acontecido antes. A. fez muitas reclamações sobre o Rio de Janeiro, passando por excesso de mosquitos até a receptividade. Ele disse que, na Colômbia, tinha sentido muito mais hospitalidade das pessoas do que por aqui. Era nítido que ele estava chateado com o fato de não ter achado a bandeira. Aquilo era muito simbólico para ele, considerando que encontramos bandeiras de uma grande variedade de nações. Para ele, mexicanos não eram tão queridos no Brasil quanto os estrangeiros de outras nacionalidades.

A situação nos leva a pensar sobre as representações no Tinder novamente. De fato, estrangeiros que não fazem parte do círculo das representações estéticas 


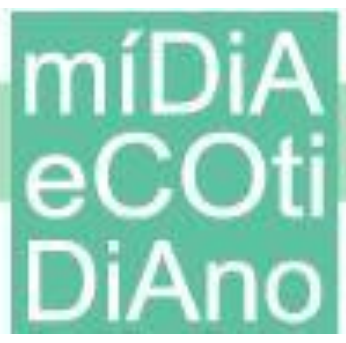

ocidentais muitas vezes não recorrem a esses símbolos identitários, isso porque interpretam que isso não os valoriza. Para A., os seus traços étnicos indígenas também influenciavam na (não) receptividade dos brasileiros, que em sua visão valorizavam seus companheiros europeus e norte-americanos de hospedagens.

$\mathrm{Na}$ semana seguinte ele seguiu viagem, demonstrou agradecimento pela experiência de viagem que teria sido, em suas palavras, "única". Depois daqueles encontros com A., com o olhar estimulado pela pesquisa, foi constatado que, muito mais do que mostrar um pouco da cidade do Rio de Janeiro, houve uma imersão inversa na cultura mexicana. Em perspectiva pessoal, foi possível aprender que os Burritos $^{10}$ passaram a ser mais interessantes que os conhecidos tacos mexicanos. Foi possível descobrir que Julietas Venegas é muito mais famosa que Thalia; que "borracharia", em português, é uma palavra muito engraçada para eles por aludir a "borracho", que significa "bêbado"; que Cancún para ele nem era México e que os turistas tinham mesmo de conhecer era Oaxaca.

Percebemos, assim, que os símbolos das identidades nacionais partilhados inicialmente no Tinder por A. ficaram de lado à medida que a interação saiu da superficialidade, sendo possíveis trocas que superavam os imaginários construídos, sobretudo, por produtos da cultura de massa, como novelas e seriados. Em trocas mais ricas, os estereótipos identitários não apareciam, mas diálogos sobre subjetividades, o que proporcionou outras experiências de trocas interpessoais, e que levaram ambos a conhecer um pouco do comportamento e também da cultura do outro. Concluímos também que os estrangeiros no Brasil possuem diferentes experiências de hospitalidade, e isso está relacionado diretamente aos imaginários que temos desses países. Confrontamos nessa experiência empírica a observação e vivência da vida cotidiana e um olhar para os imaginários coletivos compartilhado nessa troca intercultural.

\section{Considerações finais}

Ao longo da pesquisa à qual a presente análise está vinculada, percebemos que os imaginários sobre as identidades culturais e nacionais aparecem recorrentemente

\footnotetext{
${ }^{10}$ Prato tradicional da culinária do México consistindo de uma tortilla de farinha recheada.
} 


\section{míDiA

nas interações entre estrangeiros e brasileiros residentes no Rio de Janeiro suscitadas pelo aplicativo de relacionamento Tinder. Foi possível constatar nas representações de estrangeiros no aplicativo de relacionamentos que se recorreu a determinados símbolos e imagens como forma de iniciar a imersão na cidade, por meio dos interagentes brasileiros que figuram como parte integrante da localidade.

Esses símbolos e imagens estavam em sua maioria ligados a imaginários. Assim, para a discussão, foi fundamental entender como se dá a construção dos mesmos. No caso do Brasil, a história mostra que, desde o período das grandes navegações, os relatos da diferença e dos contrastes, que vieram dos encontros, estranhamentos e negociações, influenciaram e foram responsáveis pela consolidação de imaginários coletivos.

Os meios de comunicação possuem um papel determinante nesse cenário, como destacamos, por meio de filmes, novelas ou música, ao difundir em grande escala determinadas representações culturais, que apareceram também em perfis de usuários do Tinder e em interações fora dele, como observamos em diálogos com o colaborador da pesquisa.

Entendemos que estamos diante de uma experiência social vinculada às vivências cotidianas: perceber que os laços sociais se dão nessa vivência foi fundamental para realizar e analisar os dados do campo de pesquisa. Entendemos que a sociabilidade contemporânea atinge cada vez mais complexidade com as transformações tecnológicas, sobretudo em um cenário de globalização e de trocas interculturais. Sendo assim, dentro do campo de pesquisa da Comunicação, precisamos estar atentos a esses fenômenos que demandam cada vez mais experimentações teóricas e metodológicas em suas análises.

\section{Referências}

AGIER, Michel. La condition cosmopolite. L'anthropologie à l'épreuve du piège identitaire. Paris: Éditions La Découverte, 2013.

ABREU, Regina. A capital contaminada - a construção da identidade nacional pela negação do espírito carioca. In: Antonio Herculano Lopes. (Org.). Entre Europa e África - a invenção do carioca. Rio de Janeiro: Topbooks, 2000, v. 1, p. 167-185. 


\section{míDiA eCOti
DiAno}

CAIAFA, Janice. Aventuras da cidade: ensaios e etnografias. Rio de Janeiro: Editora FGV, 2007.

CAVALCANTI, Nireu. História de conflitos no Rio de Janeiro colonial. Rio de Janeiro: Civilização Brasileira, 2013.

COUTINHO, Iluska. Leitura e análise da imagem In: BARROS, Antonio; DUARTE, JORGE (organizadores). Métodos e técnicas de pesquisa em comunicação. São Paulo: Atlas, 2014.

DURAND, Gilbert. A imaginação simbólica. Lisboa: Presses Universitaires de France, tradução de 1993.

GOTARDO, Ana Teresa. Rio para gringo: A construção de sentidos sobre o carioca para consumo turístico. 2016. 164 f. Dissertação (Mestrado em Comunicação) Faculdade de Comunicação Social, Universidade do Estado do Rio de Janeiro, Rio de Janeiro, 2016.

GUBER, Rosana. La etnografia: método, campo y reflexividad. Grupo Editorial Norma, 2001.

HALL, Stuart. Quem precisa de identidade? In: SILVA, Tomaz Tadeu (org). Identidade e diferença: a perspectiva dos estudos culturais. Petrópolis, RJ: Vozes, 2013.

HINE, Christine. Etnografía Virtual. Barcelona: Editora UOC, 2004.

LEGROS, Patrick; MONNEYRON, Fréderic; RENARD, Jean-Bruno; TACUSSEL, Patrick. Sociologia do Imaginário. Porto Alegre, Sulina, 2014.

LESSA, Carlos. O Rio de todos os brasis. Rio de Janeiro: Record. 2000.

LESSER, Jefrey. A invenção da brasilidade: identidade Nacional, etnicidade e políticas de imigração. São Paulo: Editora Unesp, 2015

MAFFESOLI, Michel. A conquista do presente. Rio de Janeiro: Rocco, 1984.

. O tempo retorna: formas elementares da pós-modernidade. Rio de Janeiro: Forense Universitária, 2012.

O tempo das tribos: o declínio do individualismo nas sociedades de massa.

Rio de Janeiro: Forense Universitária, 1998. 
POLIVANOV, Beatriz. Dinâmicas identitárias em sites de redes sociais: estudo com participantes de cenas da música eletrônica no Facebook. Rio de Janeiro: Multifoco, 2014.

REZENDE, Renata. A potência imagética e a televisão do século XXI: algumas reflexões. Revista de la Asociación Española de Investigación de la Comunicación, [S.1.], v. 3, n. 6, p. 69-76, jun. 2016. 